\title{
REVISTAMATĒRIA
}

\section{Redes epóxi/amina alifáticas com perspectivas para aplicações cardiovasculares. Propriedades biológicas in vitro}

\section{Epoxy/aliphatic amine networks with perspectives for cardiovascular applications. In vitro biological properties}

\author{
Filiberto González Garcia ${ }^{1}$, Thiago Amaro Vicente ${ }^{1}$, Alvaro Antonio Alencar de Queiroz ${ }^{1}$, \\ Olga Zazuco Higa ${ }^{2}$, Fernando José Costa Baratéla ${ }^{2}$
}

\footnotetext{
${ }^{1}$ UNIFEI - Instituto de Física e Química, Universidade Federal de Itajubá, Ave. BPS No. 1303, Bairro Pinheirinho, CEP 37500-903, Itajubá, MG, Brasil. e-mail fili@unifei.edu.br; thiagofis@hotmail.com; profaaaqueiroz@gmail.com. ${ }^{2}$ IPEN - Centro de Biologia Molecular. Instituto de Pesquisas Energéticas e Nucleares, Universidade de São Paulo, CEP 05508-900, SP, Brasil. e-mail ozahiga@ipen.br; fernandobaratela@gmail.com.
}

\section{RESUMO}

Este trabalho descreve as propriedades biológicas in vitro de três redes epoxídicas à base do éter diglicidílico do glicerol (DGEG) curadas com poli(oxipropileno) diamina (D230), isoforona diamina (IPD) e 4,4'-diamino-3,3'-dimetil-diciclohexilmetano (3DCM). As interações biológicas entre os polímeros e o sangue foram estudadas por ensaios biológicos in vitro. Estudos de adsorção de proteínas, adesão de plaquetas, atividade do lactato desidrogenase (LDH) e propriedades de tromboresistência estão apresentados. Os ensaios de adsorção de proteínas na superfície dos polímeros mostrou que as redes epoxídicas adsorvem mais albumina do que fibrinogênio. Os resultados relacionados à adesão de plaquetas, atividade do lactato hidrogenase e propriedades de tromboresistência indicaram que as redes DGEG/IPD e DGEG/3DCM exibem comportamento hemocompatível. Desta maneira, assumimos que estes polímeros epoxídicos são materiais compatíveis com o sangue.

Palavras chave: hemopatibilidade, adsorção proteica, polímeros epoxídicos.

\begin{abstract}
This work describes the in vitro biological properties of three epoxy networks based on diglycidyl ether of glycerol (DGEG) cured with poly(oxypropylene) diamine (D230), isophorone diamine (IPD) and 4,4'diamino-3,3'-dimethyl-dicyclohexylmethano (3DCM). The biological interactions between epoxy polymers and blood were studied by in vitro assays. Studies of the protein adsorption, platelet adhesion, lactate dehydrogenase (LDH) activity and thromboresistance properties are presented. The protein adsorption assays onto polymeric surfaces showed that the epoxy networks adsorbed more albumin than fibrinogen. The results about platelet adhesion, lactate dehydrogenase (LDH) activity and thromboresistance properties indicated that the DGEG/IPD and DGEG/3DCM networks show hemocompatible behavior. In this way, we can assume that these epoxy polymers are blood compatible materials.
\end{abstract}

Keywords: blood compatibility, protein adsorption, epoxy polymers.

\section{INTRODUÇÃO}

Dados da Organização Mundial de Saúde (OMS) apontam que as doenças cardiovasculares (DCVS) continuam sendo uma das principais causas de morte no mundo [1]. No Brasil, a DCVS representa impacto expressivo na mortalidade da população brasileira representando atualmente a maior causa de óbitos [2]. Dentre as DCVS destaca-se a doença arterial coronariana, cujo tratamento é feito com a implantação de stent, uma endoprótese de estrutura tubular metálica expansível que é implantada no interior de uma artéria mediante o uso de um cateter para prevenir ou evitar a obstrução do fluxo de sangue local [3-4]. Entretanto, a literatura tem mostrado um elevado índice de reestenose, ou seja; 
reestreitamento posterior dos vasos dilatados pelo stent, além do aumento da incidência de inflamação, trombose e proliferação fibromuscular [5-6].

Na fabricação de stents metálicos, o aço inoxidável 316L é amplamente utilizado e, em geral, é considerado um material biocompatível, mas é propenso à corrosão quando em contato com meios biológicos, como consequência da liberação gradual de íons metálicos, tais como o cromo, níquel e ferro no tecido circundante comprometendo a integridade mecânica do dispositivo. O processo corrosivo desencadeia intensa resposta imune local e reação inflamatória que, por sua vez, induz intensa proliferação celular [7-9].

Para solucionar o problema corrosivo muitos pesquisadores consideram como alternativa o revestimento da superfície do stent metálico com uma fina camada de polímero. Existem diversos estudos que podem ser citados: (a) Copolímeros acrílicos contendo compostos que inibem a adesão de plaquetas [10]. Filmes poliméricos de alilamina polimerizada via plasma que resultou em boas propriedades adesivas e coesivas ao substrato metálico [11]. (c) Copolímeros de poli(e-caprolactona) (PCL), poli(etileno glicol) (PEG), e carboxi-PCL (cPCL) que resultaram compatíveis com dois tipos de células de artéria coronária humana [12]. (d) Copolímeros de dextrana-graft-poli(butil-metacrilato) que resultou na formação de uma fina camada polimérica nos stents, que não quebra depois do dispositivo ser submetido à expansão e compressão além de não afetar o crescimento de células endoteliais [13].

As propriedades de biocompatibilidade e citotoxicidade de monômeros epoxídicos e de polímeros epoxídicos [14-18] tem sido relatadas, mas até a presente data, não foram observadas publicações a respeito da utilização destes polímeros para aplicações cardiovasculares. Recentemente, nossos estudos sobre a hemocompatibilidade de polímeros epoxídicos, demonstram que esses materiais possuem boas propriedades de antitrombogenicidade e adequada ausência de citotoxicidade sugerindo que tais materiais possuem propriedades biológicas favoráveis para aplicação como revestimentos de dispositivos cardiovasculares [14].

O objetivo deste trabalho foi avaliar as propriedades biológicas de formulações epoxídicas alifáticas preparadas em nossos laboratórios, especialmente desenvolvidas para o revestimento de stents cardiovasculares. Foi escolhido como monômero epoxídico o éter diglicidílico do glicerol (DGEG), devido à sua estrutura alifática que deve proporcionar materiais com maior flexibilidade, quando comparado aos materiais obtidos a partir do monômero epoxídico com estrutura aromática, em particular o éter diglicidílico do bisfenol A (DGEBA). O DGEG apresenta baixa viscosidade à temperatura ambiente $\left(25^{\circ} \mathrm{C}\right)$ o que é conveniente para as formulações de revestimento [19, 20]. Os agentes de cura escolhidos foram três diaminas alifáticas visando obter polímeros epoxídicos alifáticos com diferentes propriedades biológicas, mecânicas, adesivas e de absorção de água. Este trabalho apresenta os resultados das interações biológicas in vitro entre a superfície das redes epoxídicas preparadas e o sangue.

\section{MATERIAIS E MÉTODOS}

\subsection{Materiais}

Éter diglicidílico do glicerol (DGEG) com uma massa equivalente de grupos epóxi de 143,0 g, conforme determinado por titulação ácida [21].

As diaminas alifáticas utilizadas neste trabalho foram a isoforona diamina (IPD), 4,4'-diamino3,3'-dimetil-diciclohexilmetano (3DCM) e poli(oxipropileno) diamina (D230) com uma massa equivalente de grupos hidrogênio-amina de 42,6, 59,6 e 48,0 g, respectivamente, determinado previamente por titulação potenciométrica [22].

A Tabela 1 apresenta a estrutura química, fornecedor, pureza, massa molecular e funcionalidade dos monômeros utilizados nesse trabalho.

\subsection{Preparação das amostras}

As amostras foram preparadas por pesagem dos monômeros em proporção estequiométrica (grupos epóxi/hidrogênio amina e/a $=1$ ). Todas as misturas foram cuidadosamente agitadas durante 5 min à temperatura ambiente $\left(25^{\circ} \mathrm{C}\right)$ até assegurar uma mistura homogênea. Em seguida, as misturas líquidas foram desgaseificadas a vácuo por 10 min à temperatura ambiente $\left(25^{\circ} \mathrm{C}\right)$, depois vertidas em moldes de poli(etileno) (cilíndricos) e submetidas a $60{ }^{\circ} \mathrm{C}$ durante $4 \mathrm{~h}$. Para a etapa de pós-cura, cada amostra com uma cura incompleta nos moldes de poli(etileno) foram removidas para moldes de vidro (cilíndricos). A etapa de pós-cura para as amostras à base de 3DCM, IPD e D230 foi de $180{ }^{\circ} \mathrm{C}, 160{ }^{\circ} \mathrm{C}$ e $130{ }^{\circ} \mathrm{C}$ durante 
2 h, respectivamente e deixadas a arrefecer lentamente até atingir a temperatura ambiente. Posteriormente, as amostras (cilindros) foram removidas dos moldes e maquinadas para atingir as dimensões finais. Desta forma foram produzidas amostras na forma de discos com dimensões de $1,5 \mathrm{~cm} \mathrm{x}$ $1,5 \mathrm{~cm}$, as que foram tratadas mecanicamente para alcançar o acabamento superficial requerido. Para isto, a superfície destes discos foi submetida a polimento mecânico, primeiramente foram usados discos de carboneto de silício de grau 230, 300, 400, 500, 600 e 1200, e posteriormente foi utilizada soluçãodispersão de polimento à base de óxido de alumina de grau $0,5 \mu \mathrm{m}$ e $0,3 \mu \mathrm{m}$. Durante cada etapa de tratamento mecânico os discos foram lavados com água destilada para remover os resíduos de polimento. Finalmente as amostras na forma de discos foram secas com papel absorvente, e armazenadas em dessecador com sílica gel até sua utilização.

Tabela 1: Estrutura química e características dos monômeros utilizados.

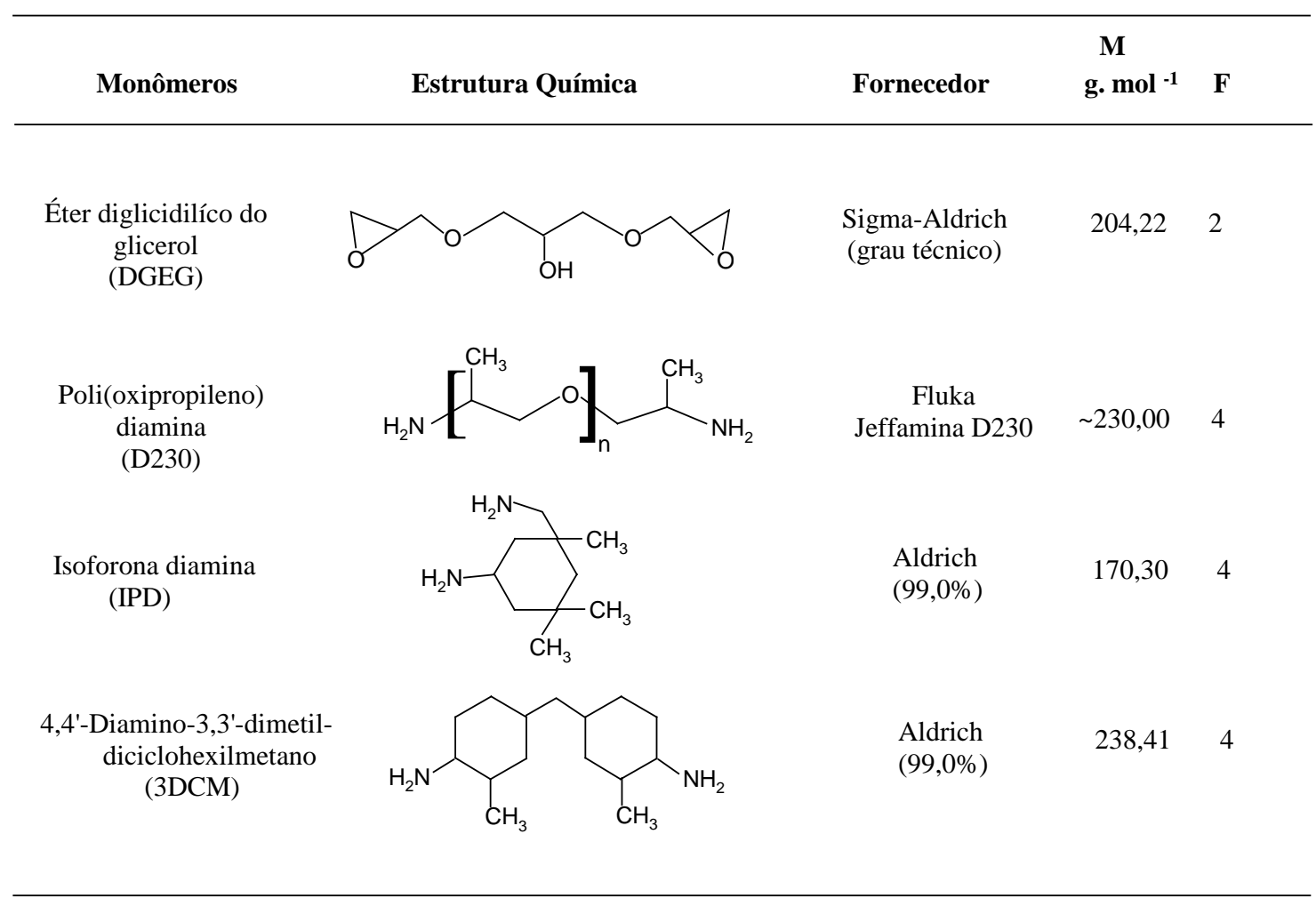

M: massa molecular, F: funcionalidade.

\subsection{FTIR e DSC}

A reação de polimerização e o processo de cura foram acompanhados através da espectroscopia com transformada de Fourier na região do infravermelho (FTIR) usando espectrômetro Perkin Elmer, modelo Spectrum 100 equipado com acessório universal de amostragem ATR com um cristal de diamante. Os espectros foram registados com uma resolução de $4 \mathrm{~cm}^{-1}$ e pelo menos 32 varreduras na faixa de $650 \mathrm{~cm}^{-1}$ a $4000 \mathrm{~cm}^{-1}$.

A temperatura de transição vítrea $T g$, e o calor residual $\Delta \mathrm{H}$, nas amostras após a cura foi determinada por calorimetria exploratória diferencial (DSC) utilizando um calorímetro Shimadzu, modelo DSC 60 em atmosfera de nitrogênio gasoso. As amostras ( 10,0 mg) foram aquecidas de 37 até $115^{\circ} \mathrm{C}$ com uma taxa de aquecimento de $10{ }^{\circ} \mathrm{C} \mathrm{min}^{-1}$ sob um fluxo de nitrogênio gasoso de $50 \mathrm{~mL} \mathrm{~min}^{-1}$. Considerou-se temperatura de transição vítrea $\mathrm{Tg}$ o início da queda da alteração na capacidade calorífica.

\subsection{Ensaios In Vitro}

\subsubsection{Comportamento trombogênico}


A compatibilidade com o sangue foi avaliada pelo ensaio de adesão plaquetária em condições estáticas utilizando sangue humano [23]. O sangue foi coletado de doadores saudáveis, de acordo com a Declaração de Helsinki [24] e aprovado pelo comitê de ética local.

Para os estudos de adesão de plaquetas, discos com dimensões de 1,5 cm x 1,5 cm de cada amostra após a cura, e do tratamento mecânico foram incubados durante $1 \mathrm{~h}$ em tampão fosfato salino (PBS, 0,1 $\mathrm{M}, \mathrm{pH} 7,4)$ a $37^{\circ} \mathrm{C}$. O ensaio foi realizado depositando $2 \mathrm{~mL}$ do sangue fresco em cada uma das cinco superfícies de teste. Após o tempo de contato de $180 \mathrm{~s}$ a $37^{\circ} \mathrm{C}$, as superfícies foram lavadas suavemente com tampão PBS para remover as plaquetas não aderidas e em seguida foram fixadas em solução de glutaraldeído (2,0\%). A seguir as amostras foram mergulhadas em solução salina tamponada (PBS, pH $7,4)$ e lavadas por 15 min por três vezes para remoção das plaquetas não aderidas por interação com as superfícies poliméricas. A desidratação das amostras foi feita por imersão durante 15 min em cada uma das soluções de concentrações crescentes de etanol (30, 50, 70, 90, 95 e 100\%). O estudo da morfologia das plaquetas aderidas sobre a superfície das amostras foi realizado por microscopia eletrônica de varredura (MEV) usando um microscópio JEOL, modelo JSM-7401F. Neste estudo foi utilizado o vidro como controle positivo.

A quantidade de plaquetas aderidas na superfície dos polímeros após exposição ao sangue foi avaliada através da atividade da enzima lactato desidrogenase (LDH) [25]. Sangue humano foi coletado de um voluntário saudável em tubo contendo o anticoagulante de citrato de sódio (citrato de sódio a 3,2\% na proporção de 9 partes de sangue para 1 do anticoagulante) e centrifugado a 1500 rpm durante 15 min para preparar o plasma rico em plaquetas (PRP). Foi depositado $1 \mathrm{~mL}$ de PRP em cada uma das superfícies dos polímeros e incubado a $37^{\circ} \mathrm{C}$ por $1 \mathrm{~h}$. Após este período as superfícies poliméricas foram lavadas com solução tampão PBS $(0,1 \mathrm{M}$; pH 7,4$)$ para remover as plaquetas, que não se ligaram à superfície do polímero.

A etapa seguinte foi adicionar sobre a superfície de cada amostra $50 \mu \mathrm{L}$ de solução Triton-X100 $(1 \% \mathrm{v} / \mathrm{v})$ deixando em contato durante $5 \mathrm{~min}$ à temperatura ambiente $\left(25^{\circ} \mathrm{C}\right)$ para desprender as plaquetas aderidas e, imediatamente avaliar a atividade LDH através de medida de absorção ótica a $340 \mathrm{~nm}$. As medidas de absorbância foram feitas em intervalos de tempo de $1 \mathrm{~min}$ e a atividade LDH foi calculada de acordo com procedimento indicado no kit utilizado.

\subsubsection{Tromboresistência}

A tromboresistência das superfícies dos materiais foi avaliada pelo método adaptado da cinética do tempo de coagulação [26, 27]. O sangue foi coletado de um voluntário saudável e adicionado $0,5 \mathrm{~mL}$ sobre a superfície de cada material. Após um período predeterminado compreendido entre 5 min e 60 min, os materiais foram transferidos para placas de Petri contendo $20 \mathrm{~mL}$ de PBS pH 7,4 e foram incubados por 5 min a $37^{\circ} \mathrm{C}$. As células vermelhas do sangue, que não ficaram aderidas na superfície do material foram hemolisadas, e a hemoglobina livre dispersada em água destilada e deionizada à temperatura ambiente (25 $\left.{ }^{\circ} \mathrm{C}\right)$. A concentração de hemoglobina livre foi medida através da espectroscopia UV-Vis monitorando a absorbância a $540 \mathrm{~nm}$. Os valores de absorbância foram representados graficamente em função do tempo de contato com o sangue. Os resultados obtidos correspondem ao valor médio de três medidas (n=3).

\subsubsection{Adsorção proteica}

Neste procedimento foram utilizadas as proteínas albumina de soro humano (HSA) e fibrinogênio humano (HFb) (Sigma-Aldrich). Inicialmente foram preparadas soluções das proteínas de HSA e HFb na concentração de $0,1 \mathrm{mg} / \mathrm{mL}$ em solução tampão PBS (10 mM, pH 7,4).

Em células de adsorção de Teflon ${ }^{\circledR}$ contendo as superfícies poliméricas foi injetada inicialmente a solução de PBS, para deslocar o ar e produzir um ambiente fisiológico para o estudo da interação entre as proteínas séricas e as superfícies sintéticas. Em seguida as células foram termostatizadas na temperatura fisiológica $\left(37^{\circ} \mathrm{C}\right)$. Uma bomba peristáltica foi utilizada para a introdução das soluções proteicas na célula de adsorção utilizando uma velocidade de $500 \mu \mathrm{L} \min ^{-1}$ a fim de se determinar a cinética de adsorção da proteína sérica nas superfícies poliméricas. Foram utilizadas células individuais para as proteínas HSA e HFb. A cinética do processo de adsorção foi estudada durante tempos predeterminados de 10, 30, 60, 90 e $120 \mathrm{~min}$. Após cada intervalo de tempo de adsorção foi extraída uma alíquota de 50 $\mu \mathrm{L}$ de solução de proteína da célula de adsorção. As soluções extraídas foram misturadas com $2 \mathrm{~mL}$ de solução de Coomassie Brilliant Blue G-250 (CBB-G250) para a análise quantitativa de cada proteína de acordo com o método de Bradford [28]. A concentração de cada proteína (HSA e HFb) nas células de adsorção após o contato com as superfícies poliméricas foi calculado utilizando uma curva de calibração. 
A quantidade de proteína adsorvida nas superfícies poliméricas foi determinada subtraindo a concentração de proteína inicialmente adicionada da concentração de proteína no intervalo de tempo de adsorção previamente estabelecido. As medições foram realizadas em triplicata e analisadas estatisticamente utilizando o teste t de Student. A significância estatística foi considerada a um nível de confiança de $95 \%(\mathrm{p}<0,05)$.

\section{RESULTADOS e DISCUSSÃO}

\subsection{Espectroscopia FTIR e determinações por DSC}

Os espectros FTIR das amostras após a cura são mostrados na Figura 1. Nestes espectros aparecem as bandas vibracionais de adsorção em boa concordância com a literatura para o éter diglicidílico do glicerol ligado a compostos com grupos amina alifática [29] tais como:

a) Bandas de adsorção em $3387 \mathrm{~cm}^{-1}$ atribuídas à vibração do grupo hidroxilo - $\mathrm{OH}$, e bandas de adsorção em 2916 e 2860 cm $^{-1}$ associadas às vibrações de estiramento de ligações C-H do tipo sp ${ }^{3}$, atribuídas a compostos alifáticos.

b) Banda associada com o anel ciclo-alifático em $1451 \mathrm{~cm}^{-1}$.

c) Bandas de adsorção em 1367, 1340 e $1254 \mathrm{~cm}^{-1}$, associadas aos grupos metilo e metileno.

d) Banda associada ao grupo éter C-O-C em $1078 \mathrm{~cm}^{-1}$.

Observa-se que não aparece a banda de adsorção em $915 \mathrm{~cm}^{-1}$ que corresponde à banda de vibração fundamental do grupo epóxi.

Os espectros FTIR sugerem que se atingiu elevados graus de conversão no processo de polimerização, e que não há diferenças significativas nas bandas de absorção para os três materiais poliméricos estudados.

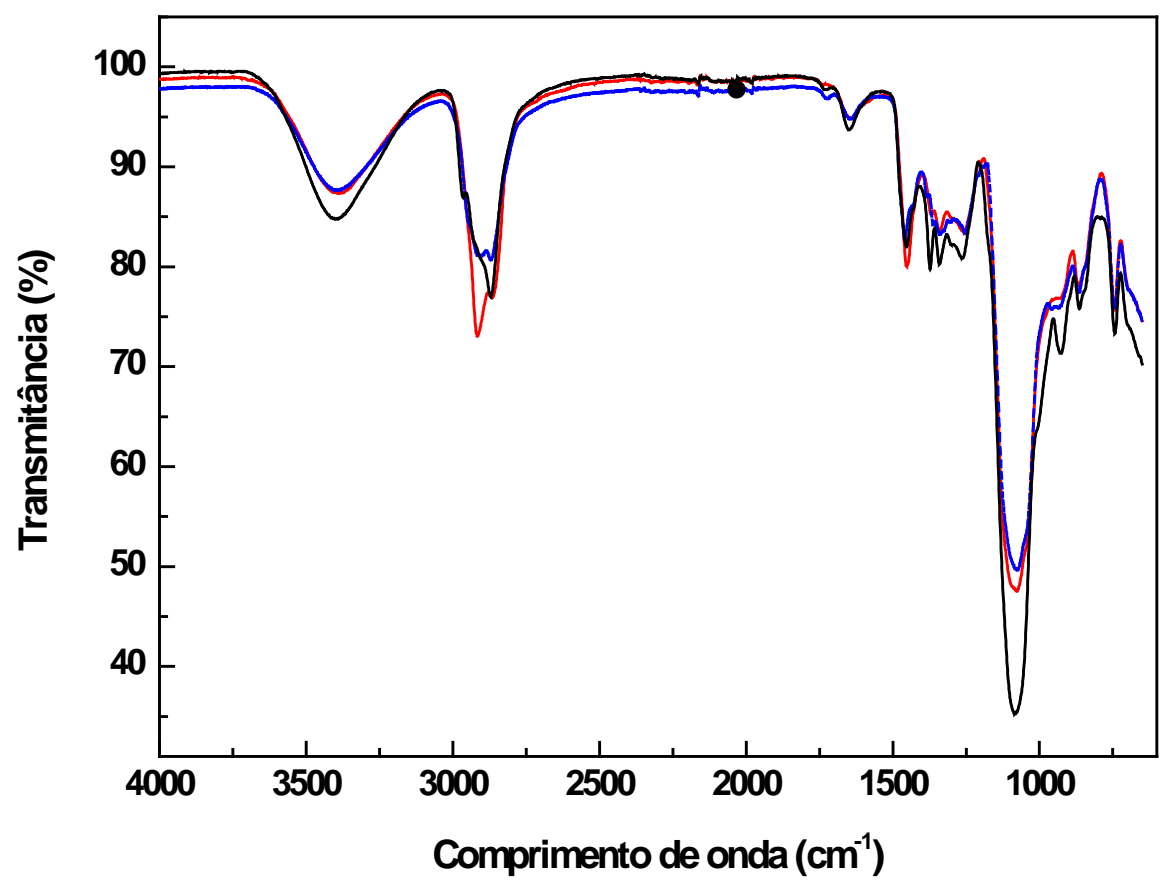

Figura 1: Espectros FTIR dos polímeros epoxídicos. DGEG/3DCM (-), DGEG/IPD ( - ) e DGEG/D230 (- $)$.

As curvas de DSC do material DGEG/3DCM são apresentadas na Figura 2. Ficou evidente que depois da primeira, e segunda varredura é obtido o mesmo valor de $\mathrm{Tg}$, $\left(42^{\circ} \mathrm{C}\right)$, e nenhum calor residual $\Delta \mathrm{H}$, foi observado tanto na primeira varredura quanto na segunda varredura. Estes resultados sugerem que a cura foi total, ou melhor, que a $\mathrm{Tg}$ do polímero chegou ao seu valor máximo. Resultados semelhantes foram obtidos para os outros polímeros e seus resultados do DSC estão apresentados na Tabela 2. Os 
resultados da Tabela 2 indicam que com o programa de cura utilizado os polímeros alcançaram alta conversão.

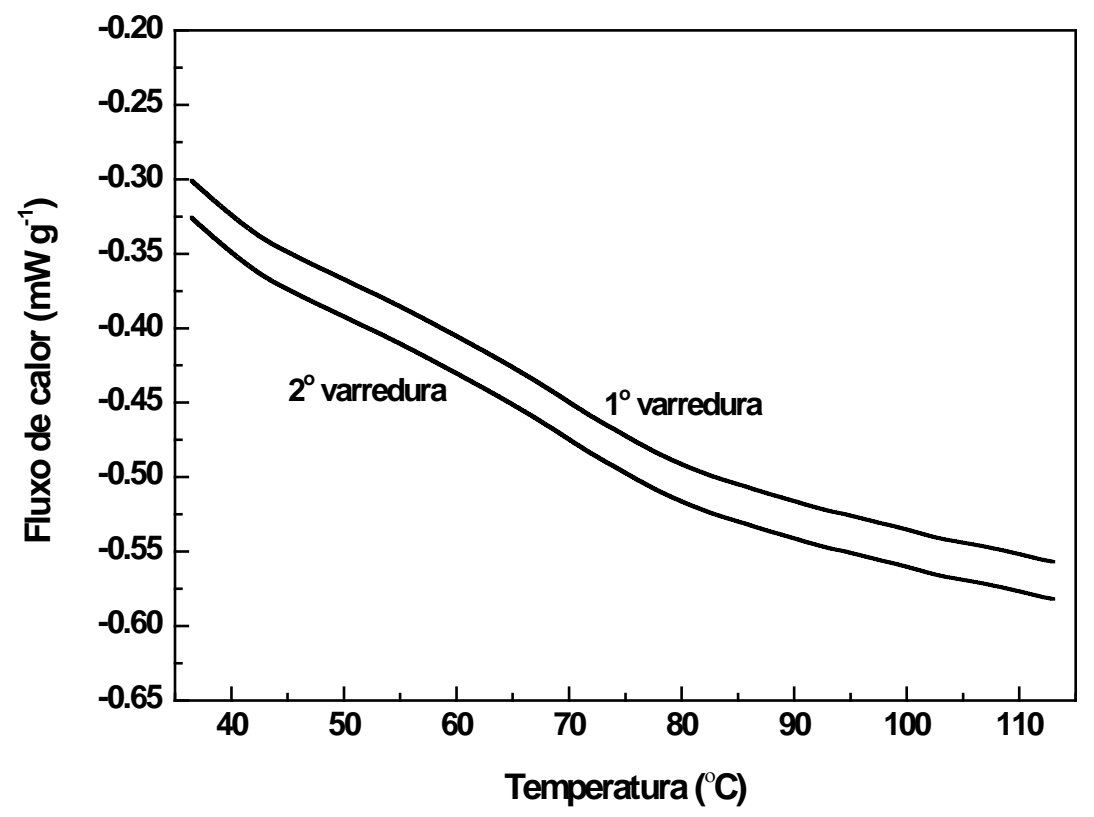

Figura 2: Curvas de DSC para o material DGEG/3DCM, após a cura.

Tabela 2: Temperatura de transição vítrea dos materiais determinada por DSC, após o programa de cura.

\begin{tabular}{ccc}
\hline Polímeros epoxídicos & $1^{\mathrm{a}}$ varredura $\left(\mathrm{T}^{\circ} \mathrm{C}\right)$ & $2^{\mathrm{a}}$ varredura $\left(\mathrm{T}^{\circ} \mathrm{C}\right)$ \\
\hline DGEG/D230 & 7,0 & 6,9 \\
DGEG/IPD & 27,2 & 27,3 \\
DGEG/3DCM & 42,0 & 42,1 \\
\hline
\end{tabular}

\subsection{Adesão de plaquetas e ativação}

As morfologias das plaquetas após a interação das superfícies poliméricas com o sangue observadas nas imagens obtidas por MEV usando ampliações de 1000x e 3000x são apresentadas nas Figuras 3 e 4. 

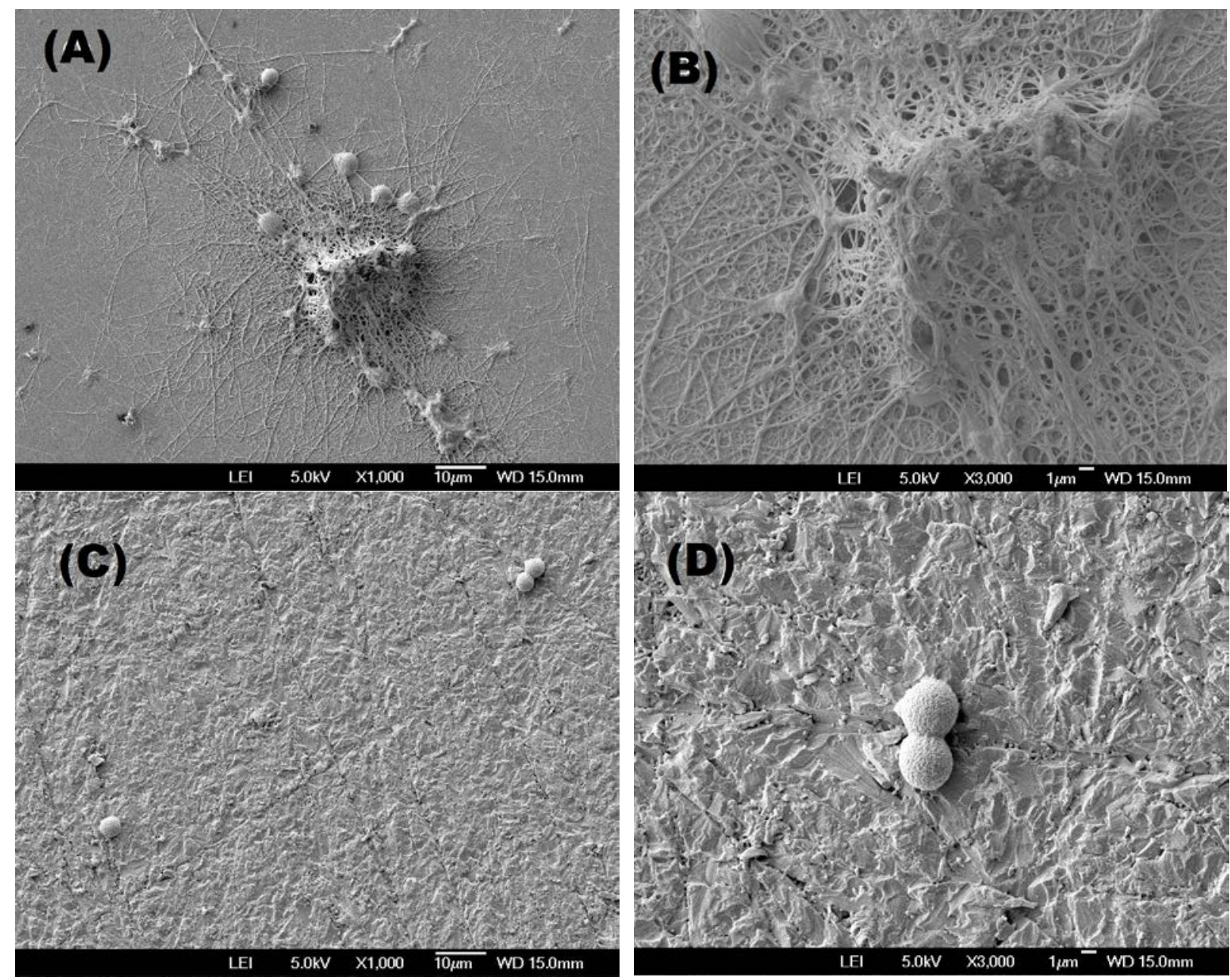

Figura 3: Micrografias MEV das superfícies do vidro e do polímero DGEG/IPD depois de um tempo de incubação de 180 s com o sangue: A e B - (Vidro) e (C e D) - Polímero DGEG/IPD.

A superfície de vidro (Fig. 3 A e B) mostrou o maior número de plaquetas ativadas deixando evidente uma maior agregação de plaquetas, rede de fibrina devido a polimerização do fibrinogênio (HFb) e formação de trombos quando comparada às superfícies dos polímeros epoxídicos sintetizados. Este resultado era esperado, pois o vidro foi utilizado como controle nestas experiências, devido à sua propriedade trombogênica bem conhecida [30, 31].

A microscopia eletrônica de varredura das superfícies dos materiais DGEG/IPD (Fig. 3 C e D) e DGEG/3DCM (Fig. 4 A e B) após o contato com o sangue evidenciam que as superfícies poliméricas apresentaram propriedades mais adequadas de hemocompatibilidade considerando que as plaquetas aderidas apresentam uma morfologia arredondada, o que sugere uma menor ativação de seu citoesqueleto. As plaquetas do sangue humano apresentam naturalmente uma estrutura discóide. Após a ativação pelo contato com a superfície sintética, exibem uma progressão de morfologias de discóides para esféricas, e para dendríticas inteiramente espalhadas, como relatado na literatura [32-36].

As plaquetas anexas e agregadas na superfície do material polimérico DGEG/D230 (Fig. 4 C e D) apresentam alterações morfológicas semelhantes como aquelas ligadas à superfície do vidro, embora em menor extensão. As plaquetas aderidas na superfície deste material mostraram uma forma dendrítica com pseudópodo de diferentes comprimentos o que indica o risco potencial de adesão de plaquetas e agregação. 

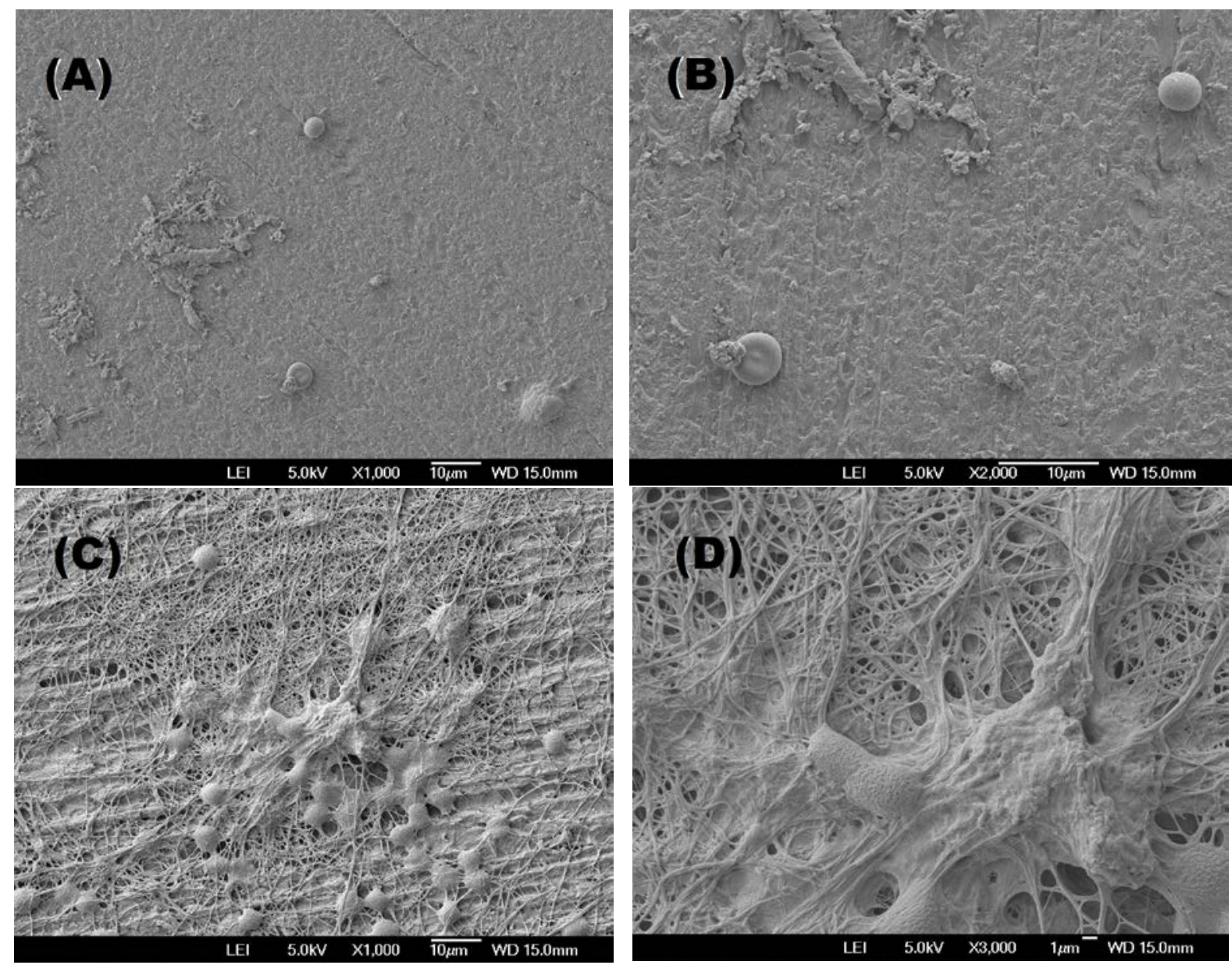

Figura 4: Micrografias MEV das superfícies dos polímeros DGEG/3DCM e DGEG/D230 depois de um tempo de incubação de 180 s com o sangue: (A e B) - Polímero DGEG/3DCM e (C e D) - Polímero DGEG/D230.

A Figura 5 mostra a porcentagem de plaquetas aderidas com morfologia discóide/esférica, mais desejáveis do ponto de vista de maior hemocompatibilidade para uma superfície sintética com o sangue [37]. O número total de plaquetas em cada imagem foi obtido pela soma do número de plaquetas com estas morfologias, e os valores calculados são o resultado da média de três imagens $(n=3)$ da superfície de cada material. Observou-se que a porcentagem de plaquetas com estas morfologias foi maior para o material DGEG/IPD, o que sugere que dos materiais estudados este apresenta a maior potencialidade de compatibilidade com o sangue.

A adesão de plaquetas na superfície dos materiais foi também avaliada pela LDH, com o objetivo de investigar o potencial das superfícies dos materiais poliméricos para capturar e ativar plaquetas. Níveis elevados de LDH estão associados à adesão de plaquetas e seus agregados [38]. Os resultados são apresentados na Figura 6. 


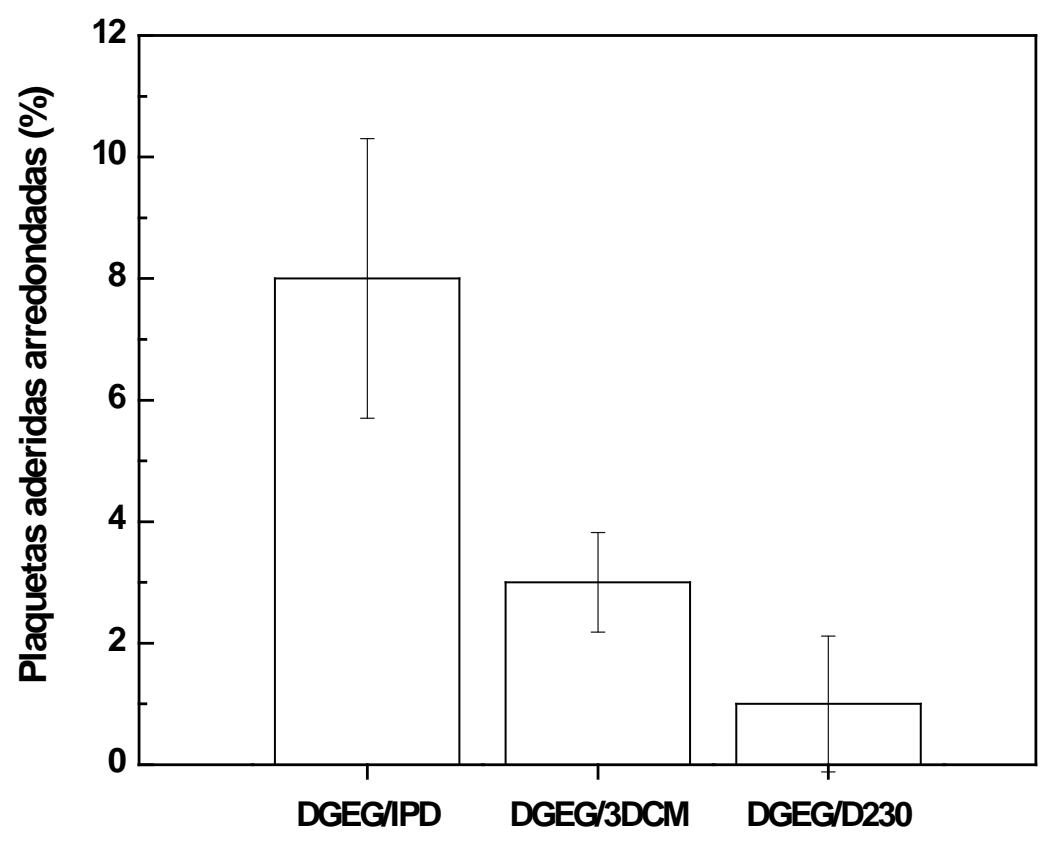

Figura 5: Porcentagem de plaquetas aderidas na superfície dos polímeros com morfologia arredondada depois do contato com o sangue.

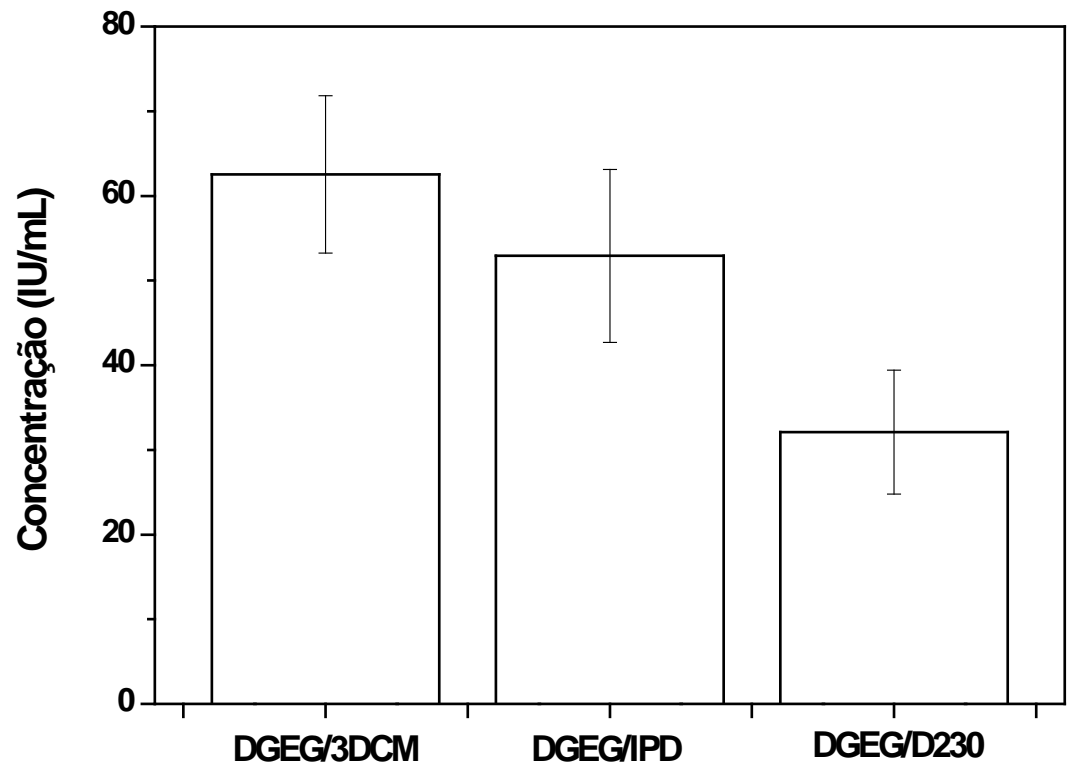

Figura 6: Adesão de plaquetas humanas nas superfícies dos polímeros sintetizados nesse trabalho avaliado pelo ensaio enzimático de LDH. 
A resposta da superfície dos materiais poliméricos determinada pelo ensaio LDH revelou uma maior adsorção de plaquetas para os polímeros DGEG/IPD e DGEG/3DCM. Em particular, a superfície do polímero DGEG/D230 mostrou menor atividade. Entretanto, a sua superfície exibe maior ativação e adesão de plaquetas, indicando que o material não pode ser considerado hemocompatível.

A topografia das superfícies dos materiais sintéticos tem sido considerada como um fator que afeta os níveis de adesão de plaquetas. Superfícies ásperas exibem um aumento na adsorção de fibrinogênio e adesão de plaquetas mesmo em contato por curto intervalo de tempo com o sangue [39]. A adesão de plaquetas e atividade (LDH) que exibem os materiais DGEG/IPD e DGEG/3DCM pode não ser totalmente atribuída à sua topografia, podendo, no entanto; estar relacionado às características intrínsecas da composição química, cristalinidade, hidrofobicidade e energia livre superficial [40].

\subsection{Tromboresistência}

A Figura 7 mostra o comportamento da coagulação do sangue em contato com as superfícies dos polímeros e do vidro. A absorbância da solução de hemoglobina hemolisada varia com o tempo e quanto maior o valor de absorbância, maior o trombo formado. O tempo de coagulação foi definido para a absorbância igual 0,1. Materiais com um tempo de coagulação maior sugere melhor hemocompatibilidade.

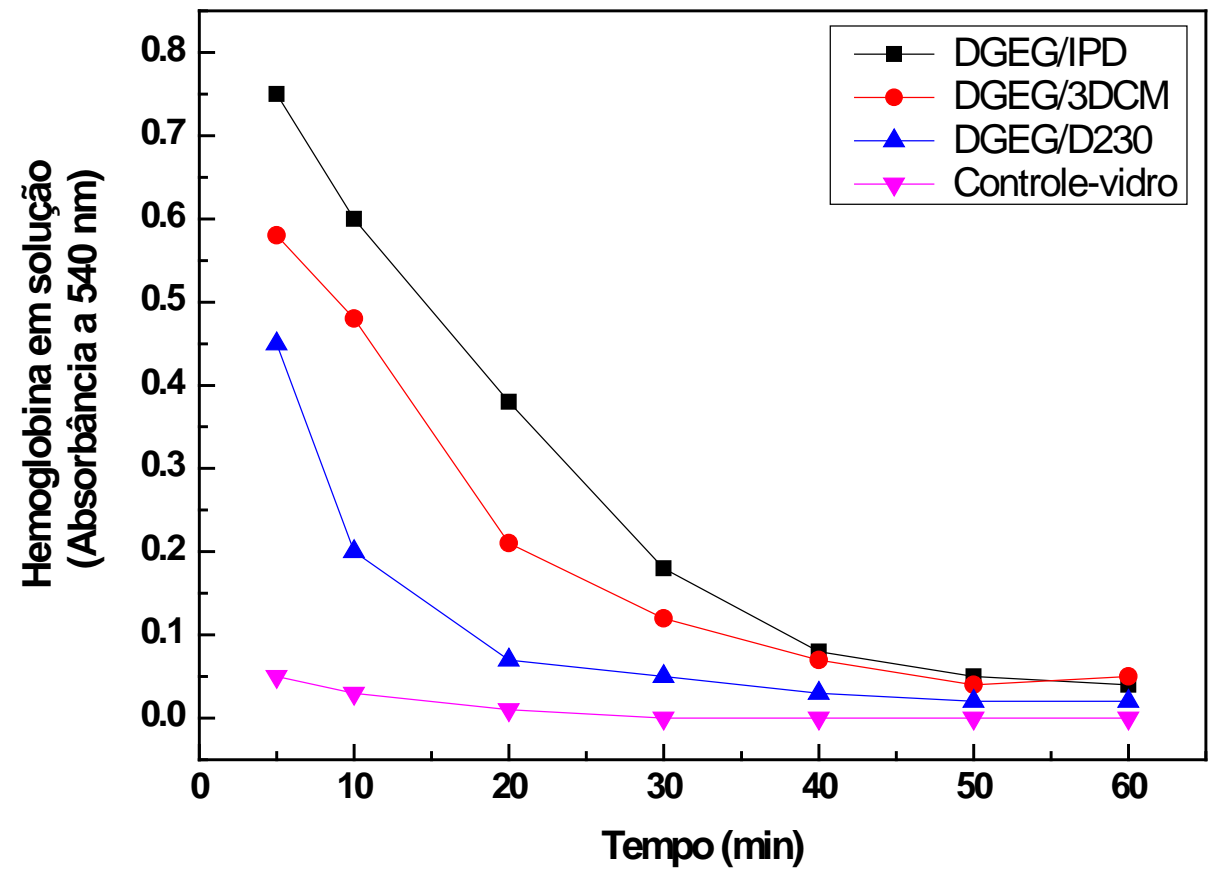

Figura 7: Formação de trombos versus tempo de contato com as superfícies dos materiais polímeros sintetizados nesse trabalho e o vidro.

Os valores de tempo de coagulação do sangue em contato com as superfícies dos materiais DGEG/IPD e DGEG/3DCM foi maior do que no DGEG/D230, indicando que os dois primeiros materiais promove uma coagulação mais lenta e, portanto são menos trombogênicos. No material DGEG/D230 é evidente as baixas absorbâncias a $540 \mathrm{~nm}$ em todos os intervalos de tempo estudados podendo ser classificado como o material mais trombogênico entre os materiais poliméricos estudados nesse trabalho. Estes resultados também indicam um menor potencial para a ativação via extrínseca para as superfícies dos materiais DGEG/IPD e DGEG/3DCM. 


\subsection{Adsorção de proteínas}

Os resultados são mostrados nas Figuras 8 e 9. A adsorção das proteínas HSA e HFb na superfície dos materiais poliméricos foram estudadas com o objetivo de examinar a extensão da interação das superfícies com as proteínas em solução fisiológica (PBS, pH 7,4). Quando uma superfície de material sintético é colocada em contato com o sangue, o primeiro evento que ocorre é a adsorção das proteínas do plasma sob a superfície, seguido de adesão de plaquetas e ativação [40, 41].

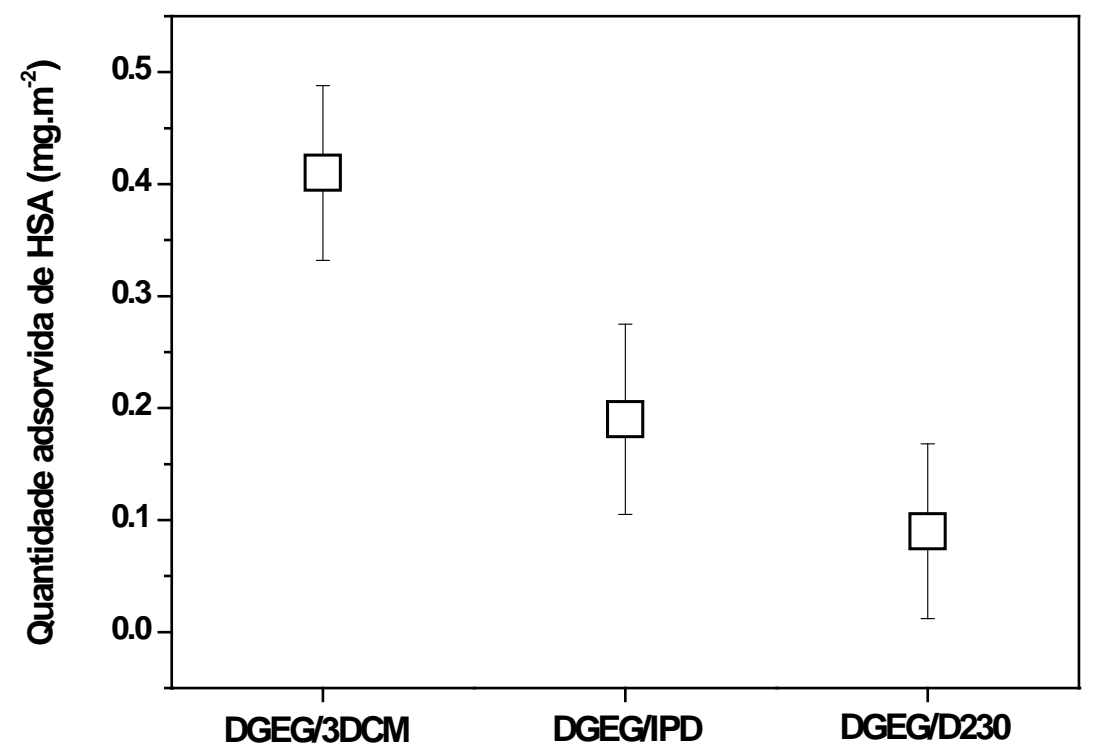

Figura 8: Quantidade de HSA adsorvida para os materiais DGEG/IPD, DGEG/3DCM e DGEG/D230.

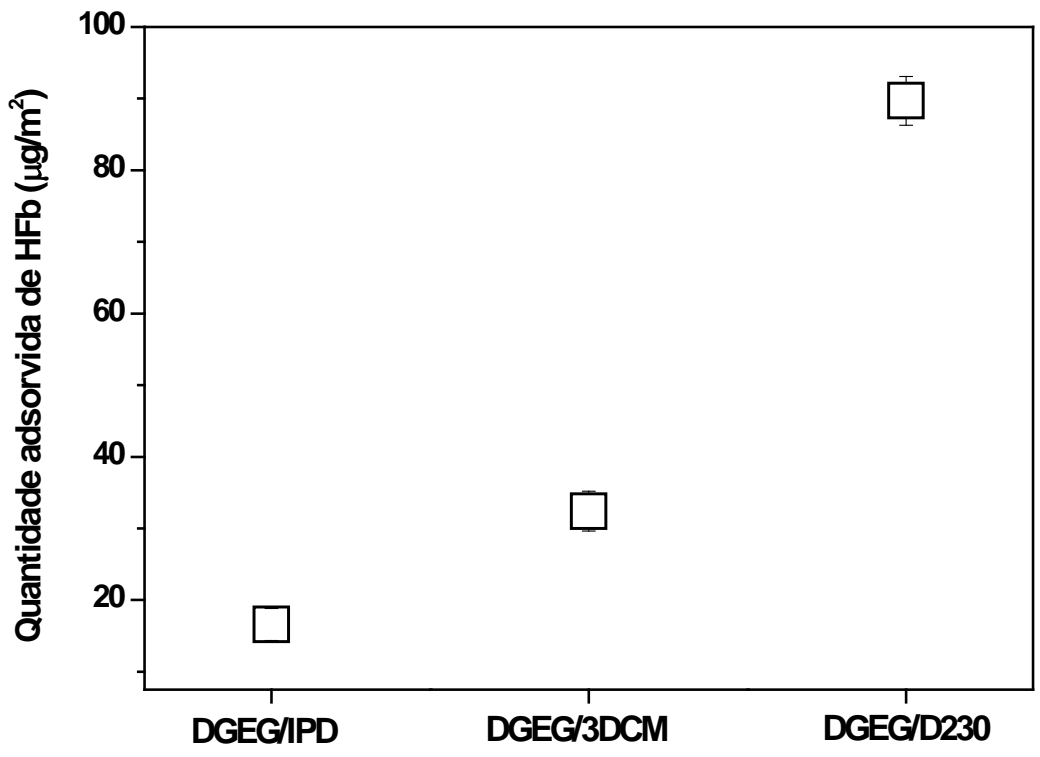

Figura 9: Quantidade de HFb adsorvida para os materiais DGEG/IPD, DGEG/3DCM e DGEG/D230. 
Na superfície do polímero DGEG/3DCM foi observada uma maior adsorção de HSA quando comparada à adsorção de $\mathrm{HFb}$, o que sugere um comportamento não-trombogênico [42]. A superfície do material DGEG/IPD mostrou uma adsorção de HSA ligeiramente mais elevada quando comparada à adsorção de $\mathrm{HFb}$, o que sugere um comportamento não-trombogênico, mas inferior ao apresentado pelo DGEG/3DCM. O material DGEG/D230 exibiu baixa adsorção de HSA e maior adsorção de HFb, indicando um comportamento mais trombogênico dentre os materiais estudados nesse trabalho.

A quantidade e o tipo de proteínas do sangue adsorvidas na interface biomaterial/sangue, governa em grande parte a ativação das plaquetas sanguíneas induzidas pelo contato com o material sintético [43]. A adsorção de HFb nas superfícies de materiais sintéticos é conhecida por acelerar a adesão e ativação de plaquetas, por outro lado, a adsorção de albumina (HSA) ajuda a inibir a ativação de plaquetas inicialmente adsorvidas na superfície sintética, inibindo assim a formação de coágulos [44]. Uma maior adsorção de HSA quando comparada à adsorção de HFb dos materiais epoxídicos pode ser um bom indicativo de baixa adesão e ativação de plaquetas por estas superfícies poliméricas. Nossos estudos anteriores com os polímeros termorrígidos à base do monômero epoxídico do éter diglicidílico do bisfenol A (DGEBA) curado com aminas alifáticas isoforona diamina (IPD) e 1-(2-aminoetil) piperazina (AEP) [14] apresentam boa concordância com os resultados obtidos neste trabalho nos ensaios de adsorção de proteínas pelos materiais DGEG/3DCM e DGEG/IPD.

\section{CONCLUSÕES}

Os resultados de FTIR e DSC evidenciaram que o programa de cura utilizado foi adequado para que todos os materiais alcançassem um alto grau de conversão no processo de polimerização. Os ensaios in vitro para os materiais DGEG/IPD e DGEG/3DCM apresentaram: alta adsorção de albumina e baixa adsorção de fibrinogênio, supressão de ativação de plaquetas, atividade do lactato desidrogenase (LDH) e boas propriedades de tromboresistência indicando que estes dois materiais são promissores para aplicações no revestimento de dispositivos cardiovasculares.

\section{AGRADECIMENTOS}

Os autores agradecem o apoio financeiro de FAPEMIG e CNPq; Processos APQ. 01736-11; APQ. 0007313 e 446735/2014-0, respectivamente.

\section{BIBLIOGRAFIA}

[1] Cardiovascular diseases mortality. World Health Organisation, 2014. Disponível em: http://gamapserver.who.int/gho/interactive_charts/ncd/mortality/cvd/atlas.html.

[2] Brasil. Ministério da Saúde. Secretaria de Atenção à Saúde. Departamento de Atenção Básica. Prevenção clínica de doenças cardiovasculares, cerebrovasculares e renais/Ministério da Saúde, Secretaria de Atenção à Saúde, Departamento de Atenção Básica. - Brasília: Ministério da Saúde, 2006.

[3] PARK, S.J., PARK, D.W., "Percutaneous coronary intervention with stent implantation versus coronary artery bypass surgery for treatment of left main coronary artery disease: is it time to change guidelines?”, Circulation: Cardiovascular Interventions, v. 2, pp. 59-68, 2009.

[4] JAKUB, P., "New Frontiers in Interventional Cardiology 2013 - Highlights from the biggest workshop in Central and Eastern Europe”, Journal of Rare Cardiovascular Diseases, v. 1, pp. 28-30, 2013.

[5] BELKACEMI, A., AGOSTINO, P.,VOSKUIL M., et al., "Drug-eluting Balloons in Coronary Artery Disease - Current and Future Perspectives”, Interventional Cardiology, v. 6, pp. 157-160, 2011.

[6] MANI, G., FELMAN, M.D., PATEL, D., et al., "Coronary stents: A materials perspective”, Biomaterials, v. 28, pp. 1689-1710, 2007.

[7] AL-MANGOUR B., MONGRAIN R., YUE S., “Coronary Stents Fracture: An Engineering Approach (Review)”, Materials Sciences and Applications, v. 4, pp. 606-621, 2013.

[8] KAJZER, W., KTAUSE, A., WALKE, W., et al., "Corrosion behavior of AISI 316L steel in artificial body fluids”, Journal of Achievements in Materials and Manufacturing Engineering, v. 31, pp. 247-253, 2008.

[9] KÖSTER, R., VIELUF, D., KIEHN, M., et al., "Nickel and molybdenum contact allergies in patients with coronary in-stent restenosis”, Lancet, v. 356, pp. 1895-1897, 2000. 
[10] RODRIGUEZ, G., FERnÁNDEZ-GUTIÉRREZ, M., PARRA, J., et al., "Bioactive polymeric system with platelet antiaggregatig activity for the coating of vascular devices”, Biomacromolecules, v. 11, pp. 2740-2747, 2010.

[11] GAlLINO, E., MASSEY, S., TATOULIAN, M., et al., "Plasma polymerized allylamine films deposited on 316L stainless steel for cardivascular stent coating”, Surface and Coatings Technology, v. 205, pp. 2461-2468, 2010.

[12] CROWDER, S.W., GUPTA, M.K., HOFMEISTER, L.H., et al., "Modular polymer design to regulate phenotype and oxidate response of human coronary artery cells for potential stent coating aplications”, Acta Biomaterialia, v. 8, pp. 559-569, 2012.

[13] BAKHSHI, R., DARBYSHIRE, A., EVANS, J.E., et al., "Polymeric coating of surface modified nitinol stent with POSS-nanocomposite polymer”, Colloids and Surfaces Part B: Biointerfaces, v. 86, pp. 93-105, 2011.

[14] GONZÁLEZ GARCIA, F., LEYVA, M.E., QUEIROZ, A.A.A., et al., "Epoxy networks for medicine applications: Mechanical properties and In vitro biological properties”, Journal of Applied Polymer Science, v. 112, pp. 1215-1225, 2009.

[15] BERRUET, R., VINARD, E., CALLE, A., et al., "Mechanical properties and biocompatibility of two polyepoxy matrices: DGEBA-DDM and DGEBA-IPD”, Biomaterials, v. 8, pp. 162-171, 1987.

[16] GECKELER, K., WACKER, R., MAETINI, F., et al., "Enhance biocompatibility for SAOS-2 osteosarcoma cell by surface coating with hydrophobic epoxy resins", Celullar Physiology and Biochemistry, v. 13, pp. 155-164, 2003.

[17] NISCHI, C., NAKAJIMA, N., IKADA, Y., "In vitro evaluation of cytotoxicity of diepoxy compounds used for biomedical modification”, Journal of Biomedical Materials Research: Part A, v. 29, pp. 829-834, 1995.

[18] KOSTORYZ, E.L., TONG, P.Y., CHAPPELOW, C.C., "In vitro cytotoxicity of solid epoxy-based dental resins and their components”, Dental Materials, v. 15, pp. 363-373, 1999.

[19] OMRANI, A., ROSTAMI, A., RAVARI, F., et al., "The relationship between composition and electrical properties of brass covered by nanocomposite coating of glycerol diglycidyl ether: An EIS and DMTA study”, Progress in Organic Coatings, v. 76, pp. 360-366, 2013.

[20] OMRANI, A., ROSTAMI, A.A., RAVARI, F., et al., "Curing behavior and structure of a novel nanocomposite from glycerol diglycidyl ether and 3,3-dimethylglutaric anhydride”, Thermochimica Acta, v. 517, pp. 9-15, 2011.

[21] American Society for Testing and Materials, ASTM, Specification D 1652. Standard test methods for epoxy content of epoxy resins, 1997.

[22] GONZÁLEZ GARCIA, F., SILVA, P.M., SOARES, B.G., et al., "Combined analytical techniques for the determination of the amine hydrogen equivalent weight in aliphatic amine epoxy hardeners", Polymer Testing, v. 26, pp. 95-101, 2007.

[23] QUEIROZ, A.A.A., BARRAK, R.B., GIL, H.A.C., et al., "Surface studies of albumin immobilized onto PE and PVC films”, Journal of Biomaterials Science Polymer Edition, v. 8, pp. 667-681, 1997.

[24] FORSTER, H.P., EZEKIEL, E., GRADY, C., "The revision of the Declaration of Helsinki: A step forward or more confusion?”, Lancet, v. 358, pp. 1449-1453, 2001.

[25] TAMADA, Y., KULIK, E.A., IKADA, Y., “Simple method for platelet counting”, Biomaterials, v. 16, pp. 259-261, 1995.

[26] IMAI, Y., NOSE, Y., “A new method for evaluation of antithrombogenicity of materials”, Journal of Biomedical Materials Research: Part A, v. 6, pp. 165-172, 1972.

[27] CHENA, J.Y., LENGA, Y.X., TIANA, X.B., et al., "Antithrombogetic investigation of surface energy and optical bandgag and hemocompatibility mechanism of $\mathrm{Ti}\left(\mathrm{Ta}^{+5}\right) \mathrm{O}_{2}$ thin films", Biomaterials, $\mathrm{v}$. 23, pp. 2545-2552, 2002.

[28] BRADFORD, M., "Rapid and sensitive method for the quantification of microgram quantities of protein utilizing the principle of protein-dye binding”, Analytical Biochemistry, v. 72, pp. 248-254, 1976.

[29] LEE, H., NEVILLE, K. “Characterization of epoxy-resin curing-agent systems”. In: Handbook of Epoxy Resins, chapter 6, McGraw-Hill, 1967. 
[30] RUCKENSTEIN, E., MARMUR, A., RAKOWER, S.R., "Sedimentation and adhesion of platelets onto a horizontal glass surface”, Thrombosis and Haemostasis, v. 36, pp. 334-342, 1976.

[31] PACKHAM, M.A., EVANS, G., GLYNN, M.F., et al., "The effect of plasma proteins on the interaction of platelets with glass surfaces”, Journal of Laboratory and Clinical Medicine, v. 73, pp. 686$697,1969$.

[32] GEMMELL, C., RAMIREZ, S., YEO, E., et al., "Platelet activation in whole blood by artificial surfaces: Identification of platelet-derived micro-particles and activated platelet binding to leukocytes as material-induced activation events”, Journal of Laboratory and Clinical Medicine, v. 125, pp. 276-287, 1995.

[33] ALLEN, R.D., ZACHARSKI, L.R., WIDIRSTKY, S.T., et al., "Transformation and motility of human platelets: details of the shape change and release reaction observed by optical and electron microscopy”, The Journal of Cell Biological, v. 83, pp. 126-142, 1979.

[34] GOODMAN ,S.L., GRASEL ,T.G., COOPER, S.L., et al., "Platelet shape change and cytoskeletal reorganization on polyurethaneureas”, Journal of Biomedical Materials Research: Part A, v. 23, pp. 105123, 1989.

[35] GOODMAN, S.L., LELAH, M.D., LAMBRECHT, L.K., et al., "In vitro vs. ex vivo platelet deposition on polymer surfaces”, Scanning Electron Microscopy, v. 1, pp. 279-290, 1984.

[36] De QUEIROZ ,A.A.A., HIGA ,O.Z., ALVES, S.B., "Digital image processing for biocompatibility studies of clinical implante materials”, Artificial Organs, v. 27, pp. 444-446, 2003.

[37] WEISENBERG, B.A., MOORADIAN, D.L., "Hemocompatibility of materials used in microelectromechanical systems: Platelet adhesion and morphology in vitro”. Journal of Biomedical Materials Research, v. 60, pp. 283-291, 2002.

[38] BAGHERI-KHOUKENJANI, S., MIRZADEH, H., "Polystyrene surface modification using excimer laser and radio-frequency plasma: blood compatibility evaluations”, Progress in Biomaterials, v. 1, pp. 18, 2012.

[39] NAIR, M.B., VARMA, H.K., JOHN, A., "Platelet-rich plasma and fibrin glue-coated bioactive ceramics enhance growth and differentiation of goat bone marrow-derived stem cells", Journal of Tissue Engineering: Part A, v. 15, pp. 1619-1631, 2009.

[40] GOVINDARAJAN, T., SHANDAS, R. "A Survey of surface modification techniques for nextgeneration shape memory polymer stent devices”, Polymer, v. 6, pp. 2309-2331, 2014.

[41] RATNER, B.D., "Blood compatibility-a perspective”, Journal of Biomaterials Science Polymer Edition, v. 11, pp. 1107-1119, 2000.

[42] BRASH, J.L., "Exploiting the current paradigm of blood-material interactions for the rational design of blood-compatible materials”, Journal of Biomaterials Science Polymer Edition, v. 11, pp. 1135-1146, 2000.

[43] XU, L-CH., SOMAN, P., AGNIHOTRI, A., et al. Atomic force microscopy methods characterizing protein interactions with microphase-separated polyurethane biomaterials”, In: Puleo D.A., Bizios R. (eds.), Biological Interactions on Materials Surface: Understanding and Controlling Protein, Cell and Tissue Response, chapter 3, Springer Publishers, 1999.

[44] WOLF, M.F., ANDERSON, M.J. "Practical approach to blood compatibility assessments: General considerations and standards”, In: Boutran J.P. (ed.), Biocompatibility and Performance of Medical Devices, chapter 8, Whoodhead Publishers, 2012. 